\title{
BMJ Open Patterns of statin utilisation for new users and market dynamics in South Korea: a 13-year retrospective cohort study
}

\author{
Kyung-Bok Son, $^{\oplus}$ SeungJin Bae ${ }^{\odot}$
}

To cite: Son K-B, Bae SJ. Patterns of statin utilisation for new users and market dynamics in South Korea: a 13-year retrospective cohort study. BMJ Open 2019;9:e026603. doi:10.1136 bmjopen-2018-026603

- Prepublication history and additional material for this paper are available online. To view these files, please visit the journal online (http://dx.doi. org/10.1136/bmjopen-2018026603).

Received 11 September 2018 Revised 16 January 2019 Accepted 28 January 2019

D Check for updates

(c) Author(s) (or their employer(s)) 2019. Re-use permitted under CC BY-NC. No commercial re-use. See rights and permissions. Published by BMJ.

Ewha Womans University, College of Pharmacy, Seoul, The Republic of Korea

Correspondence to

Dr SeungJin Bae;

sjbae@ewha.ac.kr

\section{ABSTRACT}

Objective This study analysed utilisation of statins for new statin users and assessed market dynamics of statins in South Korea.

Design This study is a retrospective cohort study. Setting The yearly claims data for statins were retrieved from the National Health Insurance Service-National Sample Cohort.

Main outcome measure We are interested in new statin users during 2003-2015 in Korea. Information on prescribed statins, including intensity of statins and entry of new and follow-on statins in the market, and healthcare institutions that prescribed the statins were also collected. In time series analysis, we estimated the effect of introduction of generics in the market, specifically for newly prescribed statin users.

Results This 13-year longitudinal study of a sample cohort provided by the National Health Insurance Service found that the incidence of new statin user increase from 838.1/100 000 persons in 2003 to 1626.9/100 000 persons in 2015. Most new users were initiated on a monotherapy that was prescribed at primary healthcare institutions. However, the statin market for new users were quite dynamic in Korea. First, the most commonly prescribed statin changed several times during the study period. Second, the use of moderate-intensity statins increased from $57 \%$ in 2003 to $92 \%$ in 2015. In line with this result, we could not observe substantial differences in prescription of statins in groups having selected diseases history. Lastly, we found market invasion or switch of statins among new statin users, specifically at primary healthcare institutions.

Conclusion Similar to other countries, the incidence of new statin users has been increased in Korea. However, the statin market in Korea is quite dynamic compared with other countries. Interestingly, discounted price of originals after the introduction of generics immediately expand markets or substitute the market particularly in primary healthcare institutions in Korea.

\section{INTRODUCTION}

Cardiovascular diseases (CVDs) account for $31 \%$ of all global deaths, taking the lives of 17.7 million people annually. ${ }^{1}$ Similarly, CVDs are among the leading causes of death in South Korea (hereafter Korea). ${ }^{2} 3$

\section{Strengths and limitations of this study}

- Given the market size of statins and a number of 'me-too' drugs and generic statins, statin utilisation, including switching drugs, in health systems has been the subject of considerable interest.

- The National Health Insurance Service-National Sample Cohort, a population-based cohort, provides public health researchers useful information regarding utilisation of health services.

- This 13-year longitudinal study of a sample cohort presented that the incidence of new statin user increase from 838.1/100 000 persons in 2003 to $1626.9 / 100000$ persons in 2015.

- Patterns of prescription and market dynamics of statins found in this study is quite different from other studies in different regions.

- Interestingly, discounted price of originals after the introduction of generics immediately expand markets or substitute the market particularly in primary healthcare institutions in Korea.

Hypercholesterolaemia is a well-established but modifiable risk factor for CVDs. ${ }^{4-8}$ Lifestyle changes and several types of medications have been recommended to control blood lipid levels. Among the medications, statins are a major drug class that functions in reducing low-density lipoprotein cholesterol (LDL-C) ${ }^{9-15}$ Specifically, statins are recommended by several clinical guidelines, including the American College of Cardiology/American Heart Association Guideline, ${ }^{10}$ the European Society of Cardiology $(\mathrm{ESC})^{9}$ and the UK's National Institute for Health and Care Excellence Guideline, ${ }^{11}$ as the drug of choice for reduction of blood lipids to prevent CVDs.

In recent decades, statins have been the most commonly prescribed drugs in the world, and their global market sales reached approximately $\$ 28.5$ billion in $2014 .{ }^{16}$ Studies from several countries reported substantial increases in prescription rates of statins, 
including increased daily doses of statins. ${ }^{17-21}$ Likewise, drug expenditure for statins has increased from 496 billion won in 2010 to 786 billion won in 2016 in Korea. ${ }^{23}$ It should also be noted that there are many 'me-too' drugs, including generics or follow on drugs, under the statin category. ${ }^{12}$ For example, atorvastatin, fluvastatin, lovastatin, pitavastatin, pravastatin, rosuvastatin and simvastatin, as well as a number of generics, are now available for patients with hypercholesterolaemia in the Korean market.

Given the market size of statins and a number of 'me-too' drugs and generic statins, statin utilisation, including switching drugs, in health systems has been the subject of considerable interest in the perspective of clinical pharmacy and public health. ${ }^{22-28}$ For instance, several European countries have restricted the prescribing of patented statins when generic statins became available at a much lower cost. ${ }^{29}{ }^{30}$ However, notably few studies have dealt empirically with the issue or included real-world data with statin users, especially in Korea. Meanwhile, it was reported that drug switching among statin users is low in Korea. ${ }^{2}$ Therefore, we selected new statin users to understand statin utilisation and market dynamics of statins in Korea. Given the limited drug switching among statin users, analysing statin utilisation of new users could be used as an important resource to evaluate the use of statins and to assess market dynamics of statins in Korea.

This study analysed the utilisation of statins for new statin users and assessed the market dynamics of statins. Specifically, this study examined characteristics of new statin users and the prescribing of statin drugs over the last 13 years, investigated the association between medical history of patients and intensity of statins and analysed market dynamics of statins, including market penetration and switching among new statin users.

\section{METHODS}

\section{Data source}

This study used the National Health Insurance Service-National Sample Cohort (NHIS-NSC), a population-based cohort established by the National Health Insurance Service. ${ }^{31}$ The dataset is composed of approximately 1 million individuals (approximately $2 \%$ of the population) selected randomly from South Koreans. The NHIS built a target population of 46605433 individuals in 2002, and then 1025340 participants was randomly selected from the target population. Specifically, systematic stratified random sampling with proportional allocation within each stratum was conducted to construct the cohort. $^{31}$

The cohort dataset consists of four databases on participants' insurance eligibility, medical treatments, healthcare institutions and general health examinations for the period from 1 January 2002 to 31 December 2015. ${ }^{31}$ The dataset provides information on demographic and socioeconomic characteristics, such as age, gender and level of income. Income level was calculated based on the insurance premium that participant pays. Also, patients' disease diagnosis was coded based on the International Classification of Diseases-10th Revision (ICD-10), and the corresponding medical expenditures such as medical and prescription information are available. The prescription information covers the date and duration of the prescription, the prescribed drugs' international non-proprietary names, dosage, the route of administration, prescribers' specialty and the types of the healthcare institution.

\section{Study design}

This study is interested in new statin users. New statin users were defined as those who had not been prescribed any statin in the year prior to the date of the first statin prescription observed in the cohort dataset. ${ }^{32}$ Therefore, new statin users in each year from 2003 to 2015 were included in the study population of each year. Specifically, the first prescription for outpatients that included any statin was set as an index date and analysed in the study.

The studied drugs include the statins atorvastatin, fluvastatin, lovastatin, pitavastatin, pravastatin, rosuvastatin and simvastatin. The information of individual drugs marketed in Korea are stated in online supplementary appendix 1 . In this study, we defined monotherapy as only one statin prescription, while we defined combination therapy as prescription for a statin plus other lipid-lowering drugs, including fibrates or ezetimibe. In addition, we searched the market of statins in Korea, including the entry of new drugs and follow on drugs and their pricing information on the website of the Ministry of Food and Drug Safety (available at http://drug.mfds.go. $\mathrm{kr} / \mathrm{html} / \mathrm{search}$ _total_download_itemPermit.jsp) and the Health Insurance Review and Assessment Service (available at https://biz.hira.or.kr/popup.ndo?formname= qya_bizcom\%3A\%3AInfoBank.xfdl\&framename=InfoBank), respectively. In Korea, copayment for medicines that prescribed for outpatients are $30 \%$ of total expenditure, including pharmacy preparation charge, thus financial burden is less likely to influence the statin adherence, unlike previous study. ${ }^{33}$

Statins were grouped into three levels of intensity $^{1034}$ : high-intensity statins, moderate-intensity statins and low-intensity statins. Daily doses can be calculated from the prescription data. High-intensity statins include atorvastatin $40-80 \mathrm{mg} /$ day, rosuvastatin $20-40 \mathrm{mg} /$ day and simvastatin $80 \mathrm{mg} /$ day. Low-intensity statins include simvastatin $10 \mathrm{mg}$ /day, pravastatin $10-20 \mathrm{mg}$ /day, lovastatin $20 \mathrm{mg} /$ day, pitavastatin $1 \mathrm{mg} /$ day and fluvastatin 20-40 mg/day. Lastly, moderate-intensity statins include atorvastatin $10-20 \mathrm{mg} /$ day, rosuvastatin $5-10 \mathrm{mg} /$ day, simvastatin $20-40 \mathrm{mg} /$ day, pravastatin $40-80 \mathrm{mg} /$ day, lovastatin $40 \mathrm{mg} /$ day, pitavastatin $2-4 \mathrm{mg}$ /day and fluvastatin $80 \mathrm{mg} /$ day.

All new statin users were classified based on their disease history, including hypertension (I10-I15), diabetes (E10E14), diseases of arteries, arterioles and capillaries (I70I79), ischaemic heart disease (I20-I25), cerebrovascular 
diseases (I60-I69), chronic obstructive pulmonary disease (J44), heart failure (I50), chronic kidney diseases (N17-N19) and atrial fibrillation (I48). Disease history was identified by the ICD-10 codes. Among these diseases, diabetes, diseases of arteries, arterioles and capillaries, cerebrovascular diseases and heart failure are related to the use of statins for CVD prevention. ${ }^{14535-37}$ Individuals were identified as having a disease history of the specific disease if they had a primary diagnosis that corresponded to each diagnosis within 3 years prior to the first prescription date. ${ }^{3738}$

Lastly, to investigate the association between the providers' characteristics and the intensity of the statin prescribed, we sorted medical institutions by primary, secondary and tertiary institutions. Primary care institutions include clinic-level medical institutions that provide medical services to outpatients. Secondary care institutions include hospital-level medical institutions that provide health services primarily to inpatients. Tertiary care institutions include superior general hospitals, designated by the Minister of Health and Welfare, that provide medical service requiring high level of expertise for treating serious disease.

\section{Data analysis}

This study used descriptive statistics to examine characteristics of new statin users and prescribed statin drugs, employed the $\chi^{2}$ test to investigate the associations between certain disease history and prescription of moderate-intensity or high-intensity statins and applied interrupted time series analysis to understand the market dynamics of statins. In time series analysis, we estimated the effect of the introduction of generics on the market, specifically for newly prescribed statin users. ${ }^{39}$ We presented the result of simple linear regression before and after the introduction of generics. ${ }^{40}$

$$
\mathrm{Y}_{\mathrm{t}}=\beta_{0}+\beta_{1} \mathrm{~T}+\beta_{2} \mathrm{X}_{\mathrm{t}}+\beta_{3} \mathrm{TX}_{\mathrm{t}}
$$

$Y_{t}:$ the number of new users that prescribed the certain statin at time $\mathrm{t}$.

T: the time elapsed since the start of the study.

$\mathrm{X}_{\mathrm{t}}$ : a dummy variable indicating the preintervention period or the postintervention period.

It should be noted that we defined the intervention year as the year when the price of originals were discounted due to the entry of follow on drugs. Generally speaking, the price of originals was discounted as soon as the entry of the follow-on drugs, in case of atorvastatin that occurred in 2008. However, the price reduction of original rosuvastatin was deferred until 2014 for the reason of valid patent that original rosuvastatin has until 2014, even though the follow-on drugs were available in 2008. Therefore, we used the year of 2008 and 2014 as the intervention year of the model for atorvastatin and rosuvastatin, respectively. Data management and analysis were performed using the R statistical software (V.3.4.1). $P$ values under 0.05 were considered to be of significance.
Ethical statement

This study used a deidentified secondary dataset. Therefore, it was exempted from review by the Institutional Review Board (IRB) of Ewha Womans University (IRB No. 158-10).

\section{Patient and public involvement}

No patients were involved in developing the research question, outcome measure and design of the study. We are unable to disseminate the results of the research directly to study participants.

\section{RESULTS}

\section{Characteristics of new statin users over time}

Table 1 presents characteristics of new statin users over time. Incidence of new statin user increase from $838.1 / 100000$ persons in 2003 to $1626.9 / 100000$ persons in 2015. There have been more female new users than male new users, while the portion of female new statin users steadily declined from $56.5 \%$ in 2003 to $50.4 \%$ in 2015. During this period, the average age of new statin users with SD remained steady (54.31-56.52 years old with 11.82-12.89 SD). We also sorted new statin users by their income quintile. The portion of the first quintile (the lowest income) increased from 13\% in 2003 to $16 \%$ in 2015 , while the portion of the fifth quintile (the highest income) decreased from $33 \%$ in 2003 to $30 \%$ in 2015 . In 2003 , hypertension accounted for the highest portion of comorbidities $(55 \%)$, followed by diabetes $(37 \%)$, ischaemic heart disease $(21 \%)$, diseases of arteries, arterioles and capillaries (14\%) and cerebrovascular diseases (12\%). These trends remained steady in 2015.

\section{Characteristics of prescribed statin drugs among new statin users}

Table 2 shows characteristics of prescribed statin drugs among new statin users. The majority of patients were prescribed with a single statin (monotherapy) when they started hypercholesterolaemia treatment, while few new users were prescribed combination therapy during the study period.

The market for monotherapy statins is dynamic. In 2003, simvastatin $(37 \%)$ was the most prescribed statin, followed by lovastatin (30\%) and atorvastatin (18\%). The market share of simvastatin had been the highest in the market from 2003 (37\%) to 2007 (50\%). During this period, the market share of atorvastatin was steady $(18 \%-$ $20 \%$ ), while the market share of lovastatin decreased from $30 \%$ in 2003 to $4 \%$ in 2007. Similarly, the market share of simvastatin decreased after 2008, while the market share of atorvastatin increased and maintained the highest from $46 \%$ in 2008 to $66 \%$ in 2013. Lastly, the market share of rosuvastatin increased from 8\% in 2013 to $36 \%$ in 2015 , while that of atorvastatin decreased from $66 \%$ to $49 \%$ during the same period. In 2015, statins for new users were an oligopoly market: atorvastatin (49\%) 


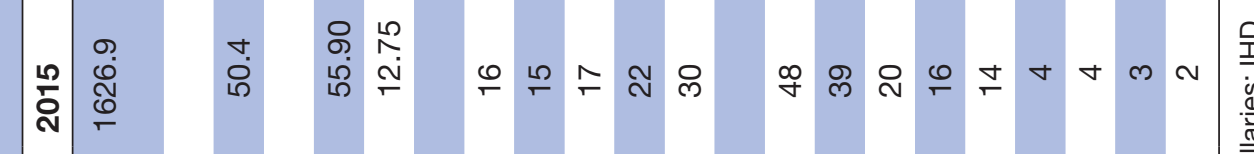

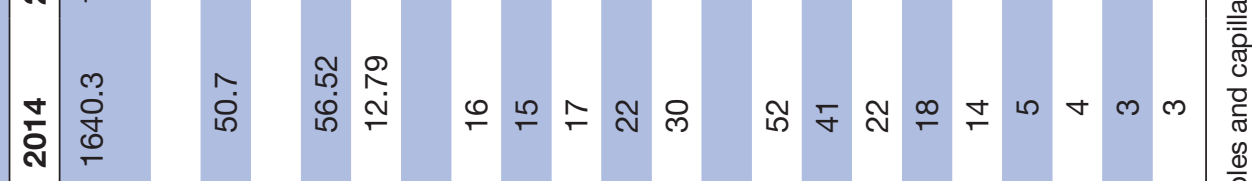

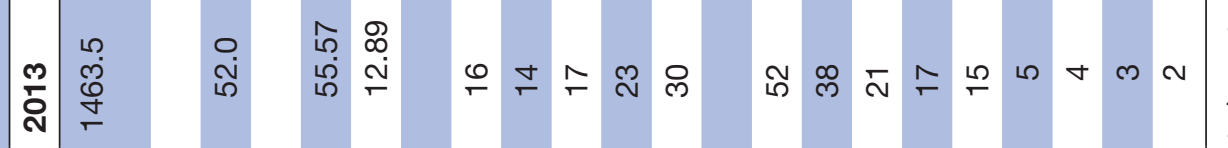

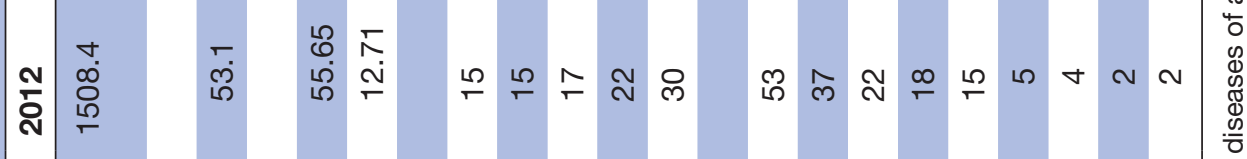

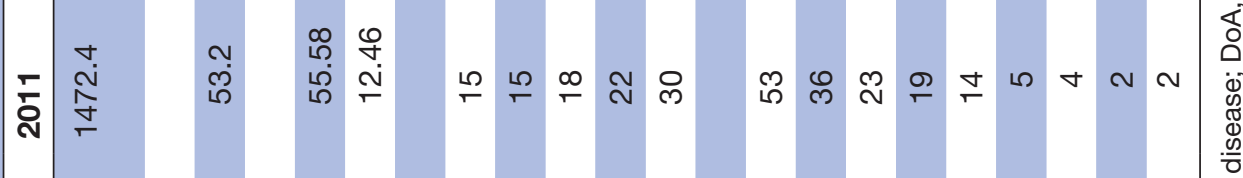

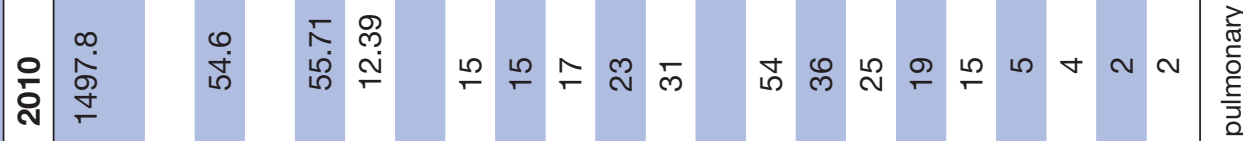

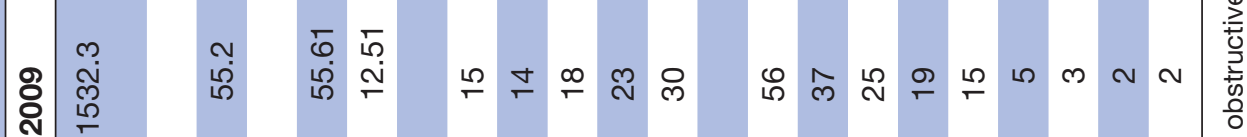

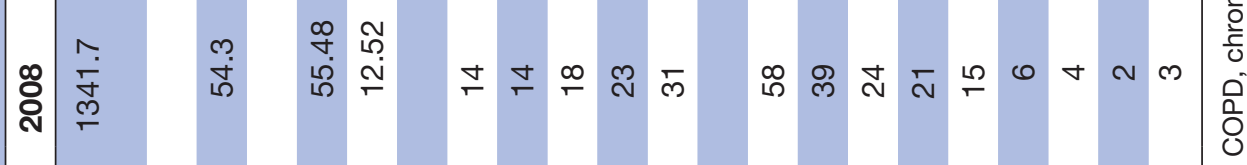

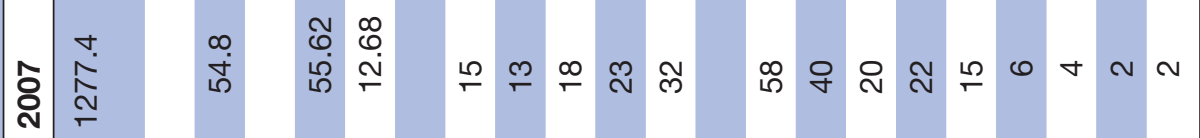

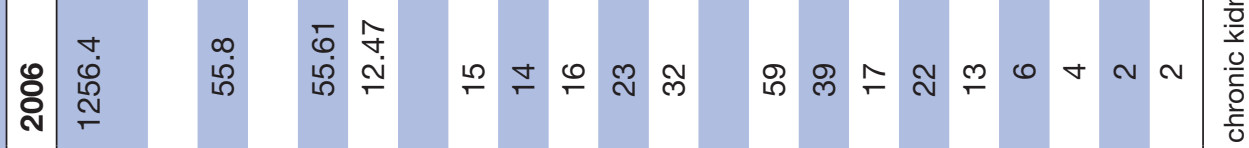

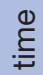

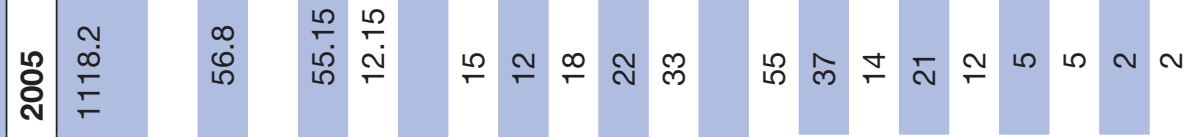

ơ

os

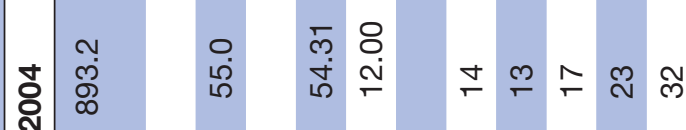

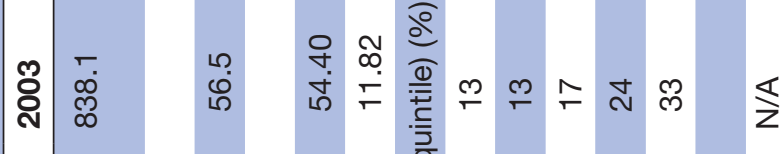

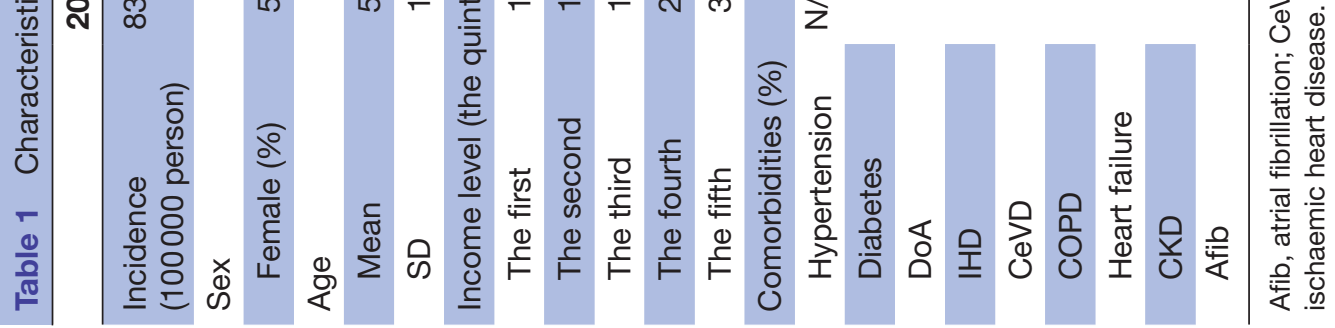


Table 2 Characteristics of prescribed statin drugs among new statin users

\begin{tabular}{|c|c|c|c|c|c|c|c|c|c|c|c|c|c|}
\hline & 2003 & 2004 & 2005 & 2006 & 2007 & 2008 & 2009 & 2010 & 2011 & 2012 & 2013 & 2014 & 2015 \\
\hline $\begin{array}{l}\text { Number of new } \\
\text { statin users }\end{array}$ & 8205 & 8835 & 11181 & 12564 & 12774 & 13333 & 15139 & 14713 & 14374 & 14639 & 14117 & 15731 & 15514 \\
\hline Monotherapy (\%) & 100 & 100 & 99 & 98 & 97 & 98 & 97 & 97 & 95 & 94 & 95 & 96 & 95 \\
\hline Atorvastatin & 18 & 19 & 20 & 18 & 18 & 46 & 61 & 61 & 62 & 63 & 66 & 51 & 49 \\
\hline Fluvastatin & 4 & 2 & 2 & 4 & 4 & 2 & 1 & 1 & 1 & 1 & 1 & 1 & 0 \\
\hline Lovastatin & 30 & 18 & 12 & 6 & 4 & 2 & 1 & 1 & 1 & 0 & 0 & 0 & 0 \\
\hline Pravastatin & 11 & 8 & 6 & 5 & 4 & 4 & 3 & 3 & 3 & 2 & 2 & 2 & 1 \\
\hline Rosuvastatin & 0 & 2 & 7 & 9 & 8 & 7 & 7 & 9 & 8 & 8 & 8 & 33 & 36 \\
\hline Simvastatin & 37 & 50 & 52 & 49 & 50 & 31 & 20 & 18 & 16 & 14 & 9 & 5 & 3 \\
\hline Combination & 0 & 0 & 1 & 2 & 3 & 2 & 3 & 3 & 5 & 6 & 5 & 4 & 5 \\
\hline High & 0 & 0 & 0 & 0 & 1 & 1 & 1 & 2 & 2 & 2 & 2 & 4 & 5 \\
\hline \multicolumn{14}{|l|}{ Institution (\%) } \\
\hline Primary & 63 & 61 & 59 & 59 & 58 & 58 & 56 & 56 & 56 & 57 & 56 & 58 & 58 \\
\hline Secondary & 20 & 23 & 25 & 26 & 26 & 25 & 27 & 28 & 28 & 28 & 29 & 29 & 29 \\
\hline Tertiary & 14 & 13 & 13 & 14 & 14 & 13 & 14 & 13 & 14 & 13 & 12 & 11 & 11 \\
\hline Others & 3 & 2 & 2 & 2 & 3 & 3 & 4 & 3 & 3 & 2 & 2 & 2 & 2 \\
\hline
\end{tabular}

was the most prescribed statin, followed by rosuvastatin $(36 \%)$.

In 2003, the prescription rates of low-intensity and moderate-intensity statins were $43 \%$ and $57 \%$, respectively. However, the prescription rate of moderate-intensity statins consistently increased to $92 \%$ in 2015 , while the prescription rate of low-intensity statins decreased to $3 \%$ in 2015. In addition, the use of high-intensity statins steadily increased during the study period. We also examined healthcare institutions that prescribed statins. In $2003,63 \%$ of new statin users were prescribed at primary healthcare institutions followed by secondary (20\%) and tertiary care institutions (14\%). During the study period, the portion of new users prescribed at primary and tertiary healthcare institutions decreased, while the portion of new users prescribed at secondary healthcare institutions increased. In 2015, 58\% of new statin users were prescribed at primary healthcare institutions followed by secondary (29\%) and tertiary healthcare institutions (11\%).

Figure 1 shows statin prescription by healthcare institutions and the intensity of prescribed statins. The first graph in figure 1 presents overall patterns of the prescription rates of low-intensity, moderate-intensity and high-intensity statins in all institution types. The remaining graphs indicate patterns of prescription rates in primary, secondary and tertiary healthcare institutions. We found that prescription rates of moderate-intensity statins were high in primary healthcare institutions, while those of high-intensity statins were high in tertiary care institutions. It is interesting to note that prescription rates of moderate-intensity statins in primary, secondary and tertiary healthcare institutions in 2003 was $48 \%, 69 \%$, and $78 \%$, respectively. However, prescription rates of moderate-intensity statins reversed in primary, secondary and tertiary healthcare institutions in 2015: 95\%, 90\% and $84 \%$, respectively.

Figure 2 presents prescription rates of selected statins, including atorvastatin, rosuvastatin and simvastatin during the study period. The first graph in figure 2 shows market shares of selected statins among new statin users. Two points are noteworthy in the perspective of market dynamics. The first market dynamic occurred during 2007-2009. Specifically, atorvastatin penetrated the market of simvastatin in this period. Similarly, the second market dynamic occurred during 2013-2015. Rosuvastatin penetrated market of atorvastatin in this period. The remaining graphs present new statin users of selected statins by primary, secondary and tertiary healthcare institutions. In this figure, we conclude that the majority of market switching of statins among new statin users occurred immediately at primary healthcare institutions.

Table 3 indicates the associations between certain disease histories and the prescription of moderate-intensity or high-intensity statins. Interestingly, no substantial differences in the prescription of statins were observed through the study period in groups with histories of diseases of arteries, arterioles and capillaries. Furthermore, patients with history of diabetes, cerebrovascular diseases and ischaemic heart disease were less likely to be prescribed moderate-intensity or high-intensity statins in 
A
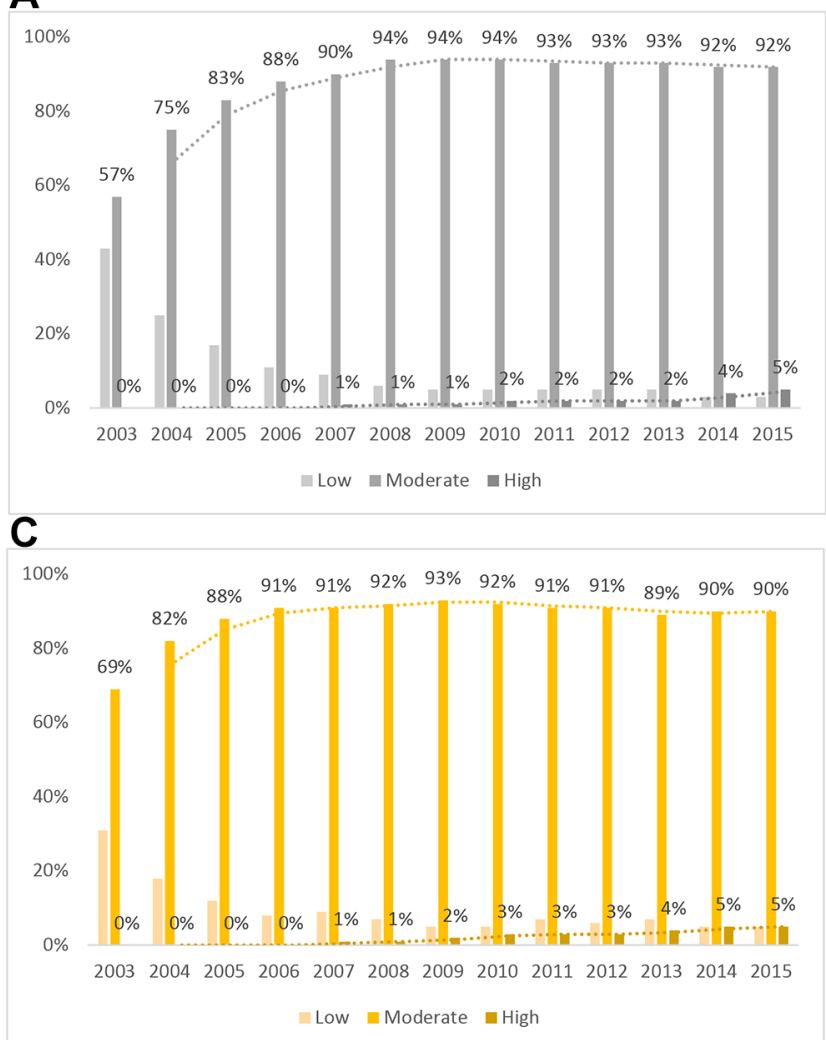

B

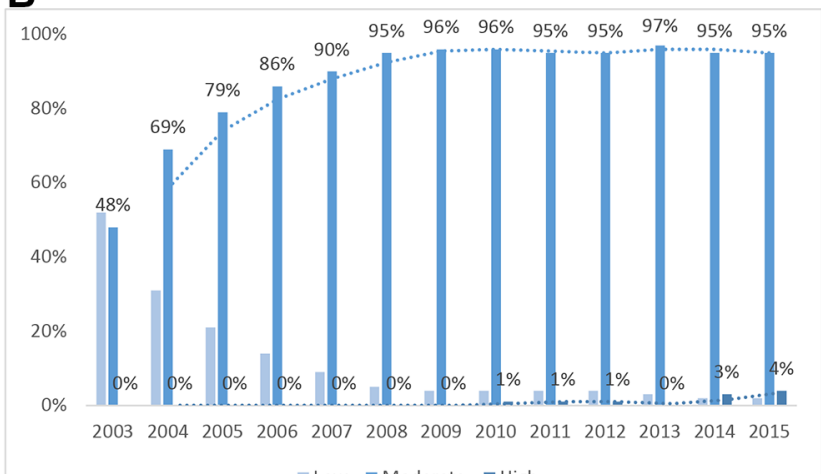

$\square$ Low $n$ Moderate $\square$ High

D

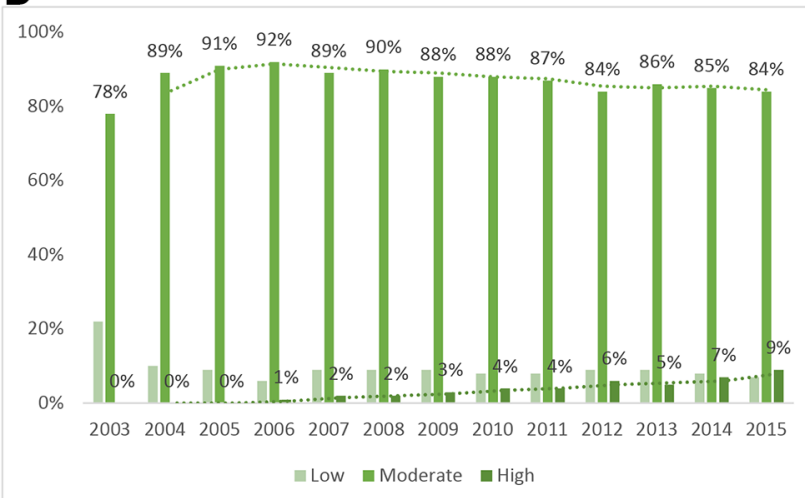

- Low $\square$ Moderate $\square$ High

Figure 1 Statin prescriptions by institution and intensity (A) all; (B) primary; (C) secondary; and (D) tertiary healthcare institutions.

several selected years. For instance, ORs were calculated at 0.78 and ranged from 0.67 to 0.91 with $95 \% \mathrm{CI}$ in 2012 for patients with diabetes.

\section{Interrupted time series analysis}

Table 4 presents results of segmented regression analysis using the interrupted time series method: $\beta_{0}$ is the preperiod intercept; $\beta_{1}$ is the preperiod slope (baseline time trend); $\beta_{2}$ is the immediate effect of the event on the intercept; and $\beta_{3}$ is the slope change after the event. In the case of atorvastatin, the immediate effect of marketing generics was 3236 new users $(\mathrm{p}<0.001)$, and the growth rate was increased by 2687 new users per year $(p<0.005)$ compared with previous trends. Similar trends were found in the case of rosuvastatin.

\section{DISCUSSIONS}

This 13-year longitudinal study of a sample cohort provided by the NHIS found that incidence of new statin user increase from 838.1/100 000 persons in 2003 to $1626.9 / 100000$ persons in 2015. Most new users were initiated on a monotherapy that was prescribed at primary healthcare institutions. In addition, the use of moderate-intensity statins increased, notably at primary healthcare institutions. Specifically, the prescription rate of moderate-intensity statins at primary healthcare institutions was low (48\%) in 2003. However, the figure was doubled in $2015(95 \%)$.
The characteristics of new statin users and healthcare institutions that prescribed statins were similar to other studies that investigated prescription patterns of all statin users in Korea. ${ }^{2}$ It is noteworthy to compare the results of statin prescription for new users with other countries $^{32}{ }^{41-44}$ : statin market for new users is quite dynamic in Korea.

First, the most commonly used statin changed several times during the study period in Korea, while atorvastatin has been the most prescribed statin during 2002-2011 in Taiwan. ${ }^{32}$ For instance, simvastatin had the highest prescription rate until 2007, while atorvastatin had the highest prescription rate after 2008. It should be noted that generics of atorvastatin were available with discounted prices compared with the originals of the previous year (approximately 68\%) in 2008, and the price of the originals was discounted approximately $20 \%$ compared with the previous year. We could find similar results in the case of rosuvastatin. Generics of rosuvastatin were available in 2010 , and the prices of generics were $\$ 0.41$ (exchange rate is 1100 won/dollar), $\$ 0.61$ and $\$ 0.81$ for a single tablet of $5 \mathrm{mg}, 10 \mathrm{mg}$ and $20 \mathrm{mg}$, respectively, which account for approximately $68 \%$ of the original counterparts. In such a case of the introduction of generics, the prices of originals would be decreased to $80 \%$ compared with the previous year. However, price reduction was deferred until 2014 in this case for the reason of valid patent that original rosuvastatin has until 2014. In the end, the 

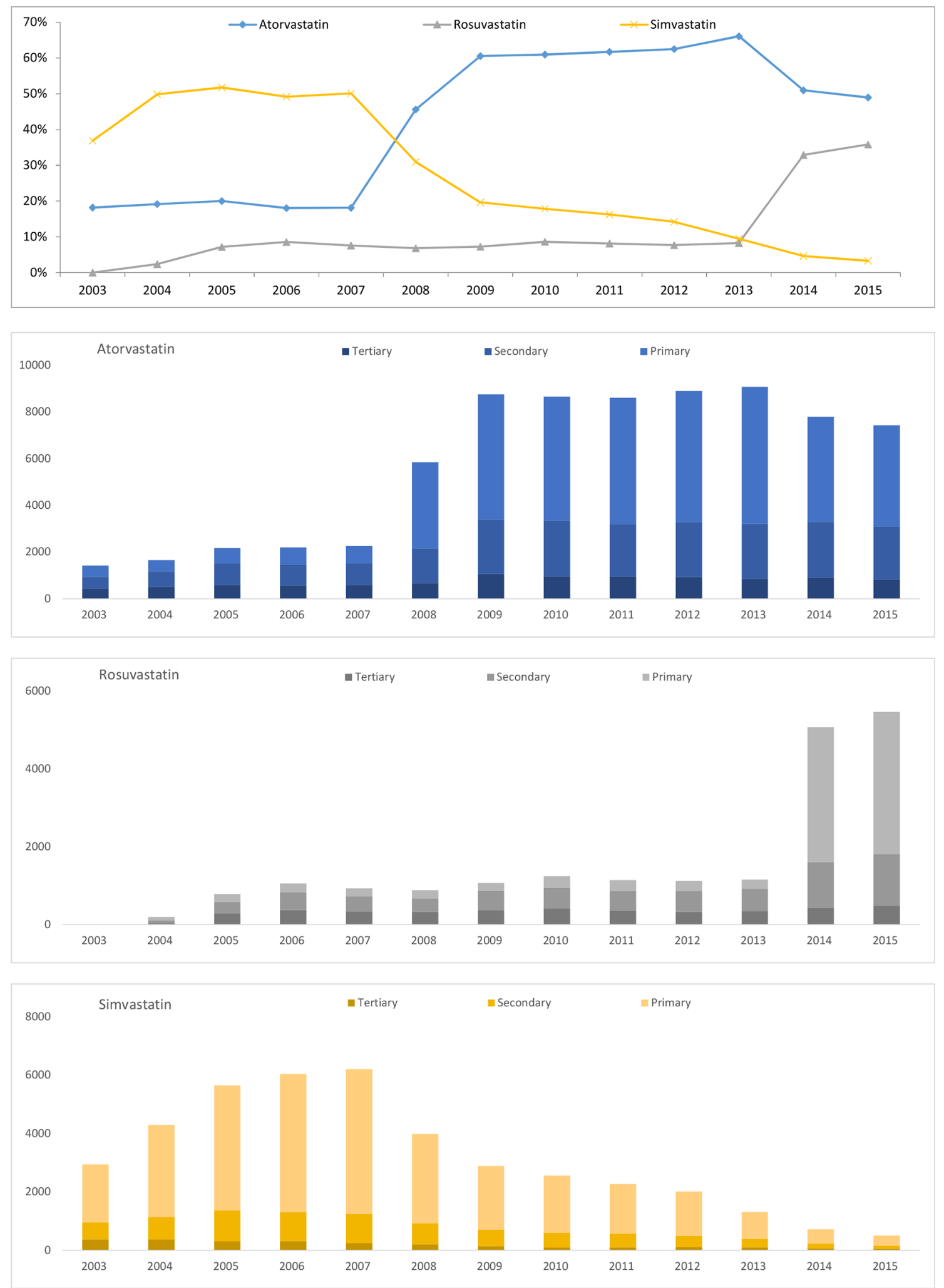

Figure 2 Prescribing rates of selected statins among new statin users.

price of original rosuvastatin decreased to approximately $80 \%$ compared with that of the previous year in 2014 . It is interesting to note the prescription rates of rosuvastatin: the market share of rosuvastatin in 2009 was $7 \%$ and slightly increased 9\% in 2010 when generics with discounted prices (approximately 32\%) were marketed and later increased 33\% in 2014 when prices of the original were discounted (approximately 20\%). It means that the sole introduction of generics is not quite effective in expanding the market in Korea. However, discounted price of the original after the introduction of generics was related with the market expansion. 


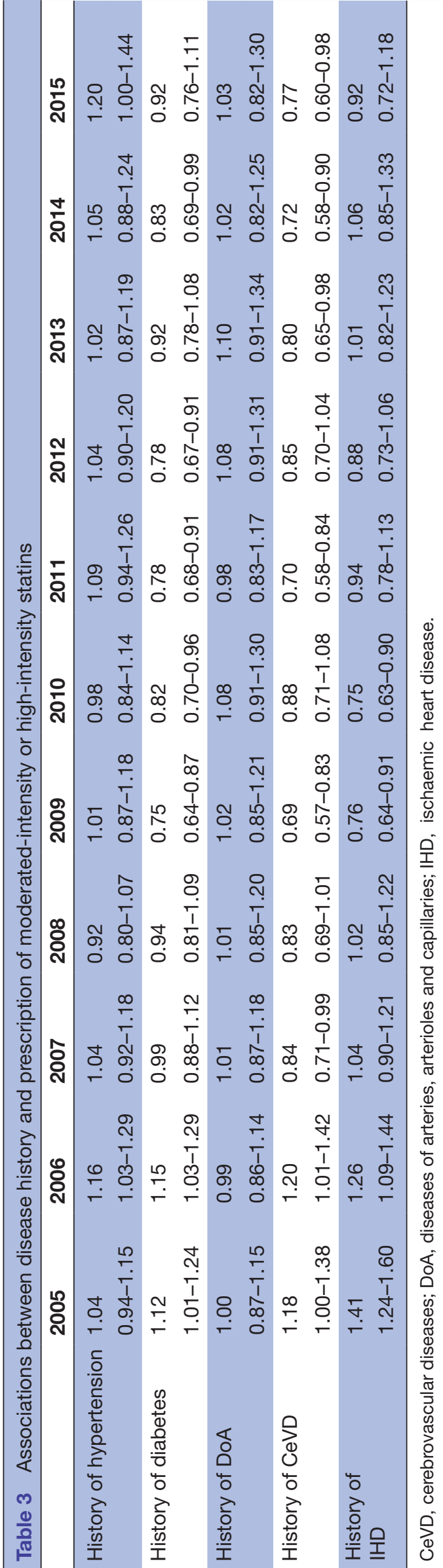

Interestingly, patterns of prescription found in this study is quite different from other studies in different regions. For instance, the incidence of new treatments decreased for atorvastatin and increased for simvastatin in Italy, Denmark and Spain ${ }^{42} 4546$. Specifically, the market share of statin for new users in Southern Italian primary care was in the order of simvastatin $(34 \%)$, atorvastatin $(26.6 \%)$ and rosuvastatin $(15.4 \%) .{ }^{42}$ Furthermore, the vast majority of new users were started treatments with simvastatin in Northern Denmark from 2004 to 2010. ${ }^{46}$ However, in Korea, simvastatin has been losing market share since 2008, and the current market share of simvastatin is marginal (3\%) in 2015.

Second, the portion of moderate-intensity statins was high in Korea, which is not common in other countries. For instance, the portion of low-intensity, moderate-intensity and high-intensity statins among new statin users in Korea was 5\%, 93\% and 2\% in 2011. However, the portion of low-intensity, moderate-intensity and high-intensity statins in Taiwan was $27 \%, 71 \%$ and $2 \%$ in the same year. Lastly, the portion of low-intensity, moderate-intensity and high-intensity statins in Spain was $4 \%, 72 \%$ and $24 \%$ from 2006 to 2010 . Given these findings, we could conclude that Korean general practitioners or specialists frequently prescribes moderate-intensity statins. In line with this result, we found no substantial differences in the prescription of moderate-intensity or high-intensity statins in groups with histories of hypertension, diabetes, diseases of arteries, arterioles and capillaries, cerebrovascular diseases and ischaemic heart disease in Korea.

Korean guidelines for the management of dyslipidaemia states that the first goal is LDL-C. ${ }^{47}$ Statin is the first-choice drug for the treatment of hypercholesterolaemia (class of recommendation I, level of evidence A) because it has a relatively low-risk profile and proven effects of decreasing CVD by lowering LDL-C. 'Statins should be prescribed' and the dose adjusted to reach the LDL-C target level for high-risk and very high-risk groups (I, A), whereas 'statin use should be considered' if LDL-C is not reduced to the first target even after lifestyle modification for weeks or months (IIa, B). The guidelines also provide dosage and administration of statins: lovastatin $20-80 \mathrm{mg}$ /day, pravastatin $10-40 \mathrm{mg} /$ day, simvastatin $20-40 \mathrm{mg} /$ day, fluvastatin $20-80 \mathrm{mg} /$ day, atorvastatin $10-80 \mathrm{mg} /$ day, rosuvastatin $5-20 \mathrm{mg} /$ day and pitavastatin $1-4 \mathrm{mg}$ /day. Interestingly, atorvastatin and rosuvastatin, the top 2 best-selling statins in Korea, was recommended as moderate-intensity and high-intensity dosage.

In addition, we found that the pricing and marketing strategies of manufacturers might encourage physicians to prescribe moderate-intensity and high-intensity statins. For instance, the manufacturer discounted the price of simvastatin $40 \mathrm{mg}$ (approximately 34\%) in 2003, and the price was the same as simvastatin $20 \mathrm{mg}$. Likewise, the other manufacturer that produce atorvastatin used the same strategy: the manufacturer discounted the price of atorvastatin $40 \mathrm{mg}(35 \%)$ in 2003 , and the price was the same as atorvastatin $20 \mathrm{mg}$; and the manufacturer 
Table 4 Results of segmented regression analysis of interrupted time series method

\begin{tabular}{|c|c|c|c|c|c|c|c|c|c|c|c|c|}
\hline & \multicolumn{3}{|l|}{ Total } & \multicolumn{3}{|c|}{ Primary care } & \multicolumn{3}{|c|}{ Secondary care } & \multicolumn{3}{|l|}{ Tertiary care } \\
\hline & Coefficient & SE & $P$ value & Coefficient & SE & $P$ value & Coefficient & SE & $P$ value & Coefficient & SE & $P$ value \\
\hline \multicolumn{13}{|c|}{ Atorvastatin (2003-2009) } \\
\hline$\beta_{1}:$ time & 221.5 & 50.8 & $<0.05$ & 75.1 & 14.0 & $<0.05$ & 108.2 & 32.5 & $<0.05$ & 38.2 & 11.7 & $<0.05$ \\
\hline$\beta_{2}$ : generic & 3236.1 & 232.8 & $<0.001$ & 2846.7 & 64.1 & $<0.0001$ & 373.2 & 148.8 & 0.087 & 16.2 & 53.5 & 0.78 \\
\hline \multicolumn{13}{|c|}{ Rosuvastatin (2004-2015) } \\
\hline$\beta_{0}$ : intercept & 1376.5 & 141.9 & $<0.001$ & 295.7 & 29.1 & $<0.001$ & 655.9 & 59.0 & $<0.001$ & 424.9 & 61.8 & $<0.0001$ \\
\hline$\beta_{1}:$ time & 76.1 & 22.9 & $<0.05$ & 13.5 & 4.7 & $<0.05$ & 42.8 & 9.5 & $<0.005$ & 19.8 & 10.0 & 0.08 \\
\hline$\beta_{2}$ : generic & 3687.5 & 251.6 & $<0.0001$ & 3163.3 & 51.6 & $<0.0001$ & 517.1 & 104.5 & $<0.0051$ & 7.1 & 109.6 & 0.95 \\
\hline
\end{tabular}

Notes: $\beta 0$ is the preperiod intercept; $\beta 1$ is the preperiod slope (baseline time trend); $\beta 2$ is the immediate effect of the event on the intercept; $\beta 3$ is the slope change after the event.

discounted the price of atorvastatin $20 \mathrm{mg}(30 \%)$ in 2007 , which was the same price as atorvastatin $10 \mathrm{mg}$. In addition, the manufacturer marketed atorvastatin $80 \mathrm{mg}$ in the market to pre-empt the high-strength statins market in 2008.

Third, we found market expansion when price of original statins were discounted. It is interesting to analyse market expansion by healthcare institutions. In cases of atorvastatin and rosuvastatin, the immediate effect of the event was large in primary healthcare institutions. For instance, the immediate effect of marketing generics of rosuvastatin was 3163 users $(\mathrm{p}<0.0000)$ and 517 users $(p<0.005)$ in primary and secondary healthcare institutions, respectively. However, the immediate effect of the event in tertiary care institutions was marginal and insignificant: $16.2(\mathrm{p}=0.78)$ for atorvastatin and 7.1 ( $\mathrm{p}=0.95$ ) for rosuvastatin. These results demonstrate that the discounted price of originals after the introduction of generics immediately expands markets, particularly in primary healthcare institutions. However, the growth rates, sorted by healthcare institutions, after the event vary according to drugs. For instance, the growth rate of atorvastatin was in the order of primary, secondary and tertiary healthcare institutions: $1597(\mathrm{p}<0.0001), 736$ $(p<0.05)$ and $352(p<0.001)$, respectively, while that of simvastatin was in the order of secondary, primary and tertiary healthcare institutions: $2243(\mathrm{p}<0.0001), 178$ $(\mathrm{p}<0.05)$ and $33(\mathrm{p}=0.80)$, respectively.

This study notably analysed the utilisation of statins for new statin users and assessed the market dynamics of statins over the last 13 years with a real-world dataset provided by the NHIS. However, this study has several limitations. First, this study used claims data that do not contain information on biochemical test data of patients, such as LDL-C level. It means that we could not assess prescription patterns by disease severity. In addition, the claims data do not contain information on whether the prescribed drugs were originals or generics. Therefore, further research is needed to assess the impact of generics on the market, including the contribution to market expansion by originals and generics, respectively. Second, this study used sample data and assumed that the data are to be representative, yet attention should be paid when generalise our results. Third, this study only used the first prescription that included any statins. Therefore, switches among statins were not included in the study. However, it would be reasonable to assume that switches among statins would be low in the Korean market. ${ }^{2}$ Lastly, we noted the dosing for statins increased in Korea and partially explained this trends with the Korean guidelines for the management of dyslipidaemia and the pricing and marketing strategies of manufacturers. However, further qualitative methods are needed to understand these interesting observations.

\section{CONCLUSIONS}

Similar to other countries, the incidence of new statin users has been increased in Korea. However, the statin market in Korea is quite dynamic compared with other countries. It is noteworthy that the portion of new statin users that were prescribed moderate-intensity statins has increased during the study period. In addition, no substantial differences in the prescriptions of statins were observed in groups with selected disease histories. Interestingly, discounted price of originals after the introduction of generics immediately expand markets or substitute the market particularly in primary healthcare institutions in Korea.

Contributors KBS designed the study, collected and analysed data, wrote and revised the manuscript. SJB revised the paper for important intellectual content. Both authors read and approved the final manuscript.

Funding The authors have not declared a specific grant for this research from any funding agency in the public, commercial or not-for-profit sectors. 
Competing interests None declared.

Patient consent for publication Not required.

Provenance and peer review Not commissioned; externally peer reviewed. Data sharing statement Additional unpublished data from the study is not available for this study.

Open access This is an open access article distributed in accordance with the Creative Commons Attribution Non Commercial (CC BY-NC 4.0) license, which permits others to distribute, remix, adapt, build upon this work non-commercially, and license their derivative works on different terms, provided the original work is properly cited, appropriate credit is given, any changes made indicated, and the use is non-commercial. See: http://creativecommons.org/licenses/by-nc/4.0/.

\section{REFERENCES}

1. WHO. Cardiovascular diseases (CVDs). 2016 http://www.who.int/ cardiovascular_diseases/en/ (Accessed 10 Aug 2018).

2. Hye-Jae L, Tae-Jin L. Impact of Price Control on Drug Expenditure and Factors Associated with the Drug Switch among Statins: Analysis of HIRA-NPS Data. Health Policy and Management 2013;23:112-23.

3. Shin S, Song H, Jang S, et al; Development of the outcome index of hyperlipidemia treatments (lipid lowering agents. Seoul: Health Insurance Review and Assessment Service, 2009.

4. Grundy SM, Cleeman JI, Merz CN, et al. Implications of recent clinical trials for the national cholesterol education program adult treatment panel iii guidelines. J Am Coll Cardiol 2004;44:720-32.

5. Sharrett AR, Ballantyne CM, Coady SA, et al. Coronary heart disease prediction from lipoprotein cholesterol levels, triglycerides, lipoprotein(a), apolipoproteins A-I and B, and HDL density subfractions: The Atherosclerosis Risk in Communities (ARIC) Study. Circulation 2001:104:1108-13.

6. Wilson PW, D'Agostino RB, Levy D, et al. Prediction of coronary heart disease using risk factor categories. Circulation 1998;97:1837-47.

7. Lee $\mathrm{KH}$, Jeong MH, Ahn Y, et al. New horizons of acute myocardial infarction: from the Korea Acute Myocardial Infarction Registry. $J$ Korean Med Sci 2013;28:173-80.

8. Lloyd-Jones DM, Larson MG, Beiser A, et al. Lifetime risk of developing coronary heart disease. The Lancet 1999;353:89-92.

9. Reiner Z, Catapano AL, De Backer G, et al. ESC/EAS Guidelines for the management of dyslipidaemias: the Task Force for the management of dyslipidaemias of the European Society of Cardiology (ESC) and the European Atherosclerosis Society (EAS). Eur Heart J 2011;32:1769-818.

10. Stone NJ, Robinson JG, Lichtenstein AH, et al. 2013 ACC/ AHA guideline on the treatment of blood cholesterol to reduce atherosclerotic cardiovascular risk in adults: a report of the American College of Cardiology/American Heart Association Task Force on Practice Guidelines. J Am Coll Cardiol 20142014;63:2889-934.

11. NICE Clinical Guideline 181. Lipid modification: cardiovascular risk assessment and the modification of blood lipids for the primary and secondary prevention of cardiovascular disease 2014. London: National Clinical Guideline Centre, 2014.

12. Weng TC, Yang YH, Lin SJ, et al. A systematic review and metaanalysis on the therapeutic equivalence of statins. J Clin Pharm Ther 2010;35:139-51.

13. Pedersen T, Kjekshus J, Berg K, et al. Randomised trial of cholesterol lowering in 4444 patients with coronary heart disease: the Scandinavian Simvastatin Survival Study (4S). Lancet 1994;344:1383-9.

14. Group HPSC. MRC/BHF Heart protection study of cholesterol lowering with simvastatin in 20536 high-risk individuals: a randomised placebocontrolled trial. The Lancet 2002;360:7-22.

15. Collins R, Armitage J, Parish S, et al. MRC/BHF Heart Protection Study of cholesterol-lowering with simvastatin in 5963 people with diabetes: a randomised placebo-controlled trial. Lancet 2003;361:2005-16.

16. IMS Institute for Healthcare Informatics. Top 20 global therapy areas 2014: England and Wales: IMS Health MIDAS, 2014.

17. IMS Institute for Healthcare Informatics. The global use of medicines: outlook through 2016. IMS Institute for Healthcare Informatics 2012.

18. Godman B, Shrank W, Andersen M, et al. Policies to enhance prescribing efficiency in europe: findings and future implications. Front Pharmacol 2010;1:141.

19. Leporowski A, Godman B, Kurdi A, et al. Ongoing activities to optimize the quality and efficiency of lipid-lowering agents in the
Scottish national health service: influence and implications. Expert Rev Pharmacoecon Outcomes Res 2018;18:655-66.

20. Woerkom M, Piepenbrink H, Godman B, et al. Ongoing measures to enhance the efficiency of prescribing of proton pump inhibitors and statins in The Netherlands: influence and future implications. J Comp Eff Res 2012;1:527-38.

21. Fraeyman J, Van Hal G, Godman B, et al. The potential influence of various initiatives to improve rational prescribing for proton pump inhibitors and statins in Belgium. Expert Rev Pharmacoecon Outcomes Res 2013;13:141-51.

22. Stargardt T. The impact of reference pricing on switching behaviour and healthcare utilisation: the case of statins in Germany. Eur $J$ Health Econ 2010;11:267-77.

23. Ahn E, Shin DW, Yang HK, et al. Treatment gap in the national health-screening program in korea: Claim-based follow-up of statin use for sustained hypercholesterolemia. J Korean Med Sci 2015;30:1266-72.

24. Kwon HY, Godman B. Do newly marketed generic medicines expand markets using descriptive time series analysis and mixed logit models? Korea as an exemplar and its implications. BMC Health Serv Res 2016;16:130.

25. Sakshaug S, Furu K, Karlstad Ø, et al. Switching statins in Norway after new reimbursement policy: a nationwide prescription study. $\mathrm{Br} J$ Clin Pharmacol 2007;64:476-81.

26. Usher-Smith J, Ramsbottom T, Pearmain $\mathrm{H}$, et al. Evaluation of the clinical outcomes of switching patients from atorvastatin to simvastatin and losartan to candesartan in a primary care setting: 2 years on. Int J Clin Pract 2008;62:480-4.

27. Health Insurance Review and Assessment Service. The results of clinical effectiveness and cost-effectiveness of hyperlipidemia treatments. Seoul: Health Insurance Review and Assessment Service, 2009.

28. Germany Federal Joint Committee. Explanatory statements on the grouping of statins, 2004. Federal Joint Committee.

29. Martikainen JE, Saastamoinen LK, Korhonen MJ, et al. Impact of restricted reimbursement on the use of statins in Finland: a registerbased study. Med Care 2010;48:761-6.

30. Godman B, Burkhardt T, Bucsics A, et al. Impact of recent reforms in Austria on utilization and expenditure of PPIs and lipid-lowering drugs: implications for the future. Expert Rev Pharmacoecon Outcomes Res 2009;9:475-84.

31. Lee J, Lee JS, Park SH, et al. Cohort profile: The national health insurance service-National Sample Cohort (NHIS-NSC), South Korea. Int J Epidemiol 2017;46:dyv319-e15.

32. Hsieh HC, Hsu JC, Lu CY. 10-year trends in statin utilization in Taiwan: a retrospective study using Taiwan's National Health Insurance Research Database. BMJ Open 2017;7:e014150.

33. Simoens S, Sinnaeve PR. Patient co-payment and adherence to statins: a review and case studies. Cardiovasc Drugs Ther 2014;28:99-109.

34. Rosenson RS, Kent ST, Brown TM, et al. Underutilization of highintensity statin therapy after hospitalization for coronary heart disease. J Am Coll Cardiol 2015;65:270-7.

35. Finegold JA, Manisty $\mathrm{CH}$, Goldacre B, et al. What proportion of symptomatic side effects in patients taking statins are genuinely caused by the drug? Systematic review of randomized placebocontrolled trials to aid individual patient choice. Eur J Prev Cardiol 2014;21:464-74.

36. Alberton M, Wu P, Druyts E, et al. Adverse events associated with individual statin treatments for cardiovascular disease: an indirect comparison meta-analysis. QJM 2012;105:145-57.

37. Lo Re V, Haynes K, Goldberg D, et al. Validity of diagnostic codes to identify cases of severe acute liver injury in the US Food and Drug Administration's Mini-Sentinel Distributed Database. Pharmacoepidemiol Drug Saf 2013;22:861-72.

38. Chen GL, Hsiao FY, Dong YH, et al. Statins and the risk of liver injury: a population-based case-control study. Pharmacoepidemiol Drug Saf 2014;23:719-25.

39. Wagner AK, Soumerai SB, Zhang F, et al. Segmented regression analysis of interrupted time series studies in medication use research. J Clin Pharm Ther 2002;27:299-309.

40. Bernal JL, Cummins S, Gasparrini A. Interrupted time series regression for the evaluation of public health interventions: a tutorial. Int J Epidemiol 2017;46:348-55.

41. Walley T, Folino-Gallo P, Stephens P, et al. Trends in prescribing and utilization of statins and other lipid lowering drugs across Europe 1997-2003. Br J Clin Pharmacol 2005;60:543-51.

42. Ferrajolo C, Arcoraci V, Sullo MG, et al. Pattern of statin use in southern italian primary care: can prescription databases be used for monitoring long-term adherence to the treatment? PLoS One 2014;9:e102146 
43. Svensson E, Beck Nielsen R, Hasvold P, et al. Statin prescription patterns, adherence, and attainment of cholesterol treatment goals in routine clinical care: a Danish population-based study. Clin Epidemiol 2015;7:213.

44. O'Keeffe AG, Nazareth I, Petersen I. Time trends in the prescription of statins for the primary prevention of cardiovascular disease in the United Kingdom: a cohort study using The Health Improvement Network primary care data. Clin Epidemiol 2016;8:123.

45. García-Gil M, Blanch J, Comas-Cufí M, et al. Patterns of statin use and cholesterol goal attainment in a high-risk cardiovascular population: A retrospective study of primary care electronic medical records. J Clin Lipidol 2016;10:134-42.

46. Svensson E, Nielsen RB, Hasvold P, et al. Statin prescription patterns, adherence, and attainment of cholesterol treatment goals in routine clinical care: a Danish population-based study. Clin Epidemiol 2015;7:213-23.

47. Kim CJ, Kim J, Kim Kl, et al. 2015 Korean guidelines for the management of dyslipidemia: executive summary (English translation). Korean Circulation Journal 2015;46:275-306. 